Atmos. Chem. Phys., 13, 9169-9181, 2013

www.atmos-chem-phys.net/13/9169/2013/

doi:10.5194/acp-13-9169-2013

(C) Author(s) 2013. CC Attribution 3.0 License.

\title{
Atmospheric processing of iron carried by mineral dust
}

\author{
S. Nickovic ${ }^{1,4}$, A. Vukovic ${ }^{2,3}$, and M. Vujadinovic ${ }^{2,3}$ \\ ${ }^{1}$ World Meteorological Organization, Geneva, Switzerland \\ ${ }^{2}$ Faculty of Agriculture, University of Belgrade, Belgrade, Serbia \\ ${ }^{3}$ South East European Virtual Climate Change Center, Belgrade, Serbia \\ ${ }^{4}$ Institute of Physics, Belgrade, Serbia \\ Correspondence to: S. Nickovic (nickovic@gmail.com)
}

Received: 3 December 2012 - Published in Atmos. Chem. Phys. Discuss.: 24 January 2013

Revised: 25 July 2013 - Accepted: 1 August 2013 - Published: 16 September 2013

\begin{abstract}
Nutrification of the open ocean originates mainly from deposited aerosol in which the bio-avaliable iron is likely to be an important factor. The relatively insoluble iron in dust from arid soils becomes more soluble after atmospheric processing and, through its deposition in the ocean, could contribute to marine primary production. To numerically simulate the atmospheric route of iron from desert sources to sinks in the ocean, we developed a regional atmospheric dust-iron model that included parameterization of the transformation of iron to a soluble form caused by dust mineralogy, cloud processes and solar radiation. When compared with field data on the aerosol iron, which were collected during several Atlantic cruises, the results from the higher-resolution simulation experiments showed that the model was capable of reproducing the major observed patterns.
\end{abstract}

\section{Introduction}

Mineral dust transported through the atmosphere carries iron-rich minerals that may play a significant role as marine nutrients when deposited into the open ocean. In soil sources, iron is almost insoluble (Zhu et al., 1997), but its solubility can considerably increase during atmospheric transport (e.g., Jickells and Spokes, 2001). The soluble form of iron is considered a critical parameter for marine bioproduction (e.g., Sholkovitz et al., 2012).

Why and how the atmospheric chemical processing of iron evolves remains controversial. There are processes identified as possible explanations for iron solubilization, but their relative importance is not yet well known. It is assumed that longer exposure to solar radiation contributes to faster iron solubilization due to the photochemical reduction of the iron (e.g., Jickells and Spokes, 2001; Hand et al., 2004). Cycling of dust particles in the clouds, in which $\mathrm{pH}$ is usually higher than 4 , and in the aerosol phase, in which pH is usually substantially lower, can significantly affect iron solubility (Shi et al., 2012). The repeated wetting of the aerosol particle surfaces during their exposure to the cloud conditions should solubilize the iron on the outer surfaces of the particle and enhance the reduction of Fe(III) (Buck et al., 2010). The biomass burning and pollution aerosols are presumed to enhance iron solubility in atmospheric aerosols (mixed dust and combustion aerosol) (e.g., Mahowald et al., 2005; Jickells and Spokes, 2001). Iron in smaller dust particles that are processed in the atmosphere for longer periods has a higher probability of conversion to the soluble form because of physical size sorting (e.g., Baker and Jickells, 2006). Finally, the soil mineralogy plays an important role in iron chemical transformation (Journet et al., 2008).

There are different approaches to parameterize the iron decay rate. Hand et al. (2004) considered that the decay rate coefficient is dependent on the incoming solar radiation and on the cloud cover. Luo et al. (2005) combined the radiation and cloud effects with the influence of the sulfate concentration of polluted air on the iron solubility. In their study, the iron fraction in the dust and the soluble iron fraction in the soils were kept constant. Both these studies specified the decay lifetime as 300 days and assumed that the iron solubility can reach a maximum value of $20 \%$ during the two weeks typically required for dust transport across the Atlantic. Moxim et al. (2011) specified that the iron solubilization rate is dependent on the acid chemical processing, 
the local sunlight and cloud processing, with the decay time ranging from $3 \mathrm{~h}$ (cloud processing of hygroscopic particles) to 23 days (chemical and photo processing). Fan et al. (2006) used a two-step mechanism for the iron processing by sulfur, which included the acid coating of the dust phase followed by the dissolution phase. For converting the hematite iron in the dust aerosol, Meskhidze et al. (2003) suggested a mechanism where iron becomes more soluble in a highly acidic, polluted environment. Ito and Feng (2010) included alkaline compounds in the aqueous chemistry, thus limiting the iron dissolution during the long-range transport over the North Pacific Ocean. These authors also demonstrated that the degree of iron solubilization is sensitive to the chemical composition of the iron-containing minerals in the dust. Shi et al. (2011b) used different kinetic rates to test the sensitivity of soil samples of different mineralogical compositions at different associated phases of the iron dissolution. They specified a decay lifetime of 8 days for the slowest dissolution phase.

Journet et al. (2008) showed that mineralogy is a critical factor for the iron solubilization. They demonstrated that most of the bio-avaliable iron in the dust originates from clays containing over $90 \%$ of the soluble iron rather than from the iron oxides (e.g., hematite), despite the high iron content in the oxides $(50-80 \%)$. The higher solubility of the clay minerals occurs because their structural iron bonds are weaker than those of the crystalline iron oxides (Paris et al., 2011).

Shi et al. (2011a) studied the potential for the iron solubilization and demonstrated that the free-to-total iron ratio, rather than the total iron itself, plays a key role in the solubilization process. They explored how weathering in the dustproductive North African soils affects the solubility of the dust-borne iron. Through physical weathering, parent soils are disintegrated by processes such as wetting and drying, erosion, and actions of plants and animals. Once parent soil has broken down into smaller elements, primary minerals of smaller soil particles are chemically transformed into secondary minerals such as oxides by the influence of water and/or atmosphere.

Laboratory studies have shown that repeated cycling of aerosol by acid processing between high and low $\mathrm{pH}$ will enhance the iron solubility (e.g., Spokes et al., 1994; Zhu et al., 1997; Baker et al., 2006). These laboratory experiments should simulate the dust cycling of dust between aerosols and clouds. For example, Baker et al. (2006) used pH 4.7 for the laboratory aerosol processing. Furthermore, Shi et al. (2011a) performed experiments by exposing soil samples to the acidic conditions in order to simulate the atmospheric conditions. Exposure of soil samples was performed through multiple $\mathrm{pH}$ cycling applied between the acidic ( $\mathrm{pH} 2)$ and circumneutral $\mathrm{pH}$ (pH 5-6) conditions. Establishment of standard tools (reference materials and protocols), as stated by Baker and Croot (2008), could help reducing differences in the solubility estimation between current methods.
In the mentioned studies, the iron solubility has been estimated, although these methods do not really reproduce the conditions under which the iron is released from aerosol particles once they are deposited onto the ocean surface (where $\mathrm{pH}$ is around 8). They show the trends in solubility that might be expected in the behavior of the aerosol in the seawater (Baker et al., 2006). With such methods, being internally consistent, the observed relative changes in the iron solubility could most probably indicate tendencies in the solubility process in seawater (Baker et al., 2006).

The bio-available fraction of the iron deposited on the ocean surface is not well characterized, but it is often assumed to be the soluble fraction (e.g., Mahowald et al., 2005; Sholkovitz et al., 2012). By compiling a large set of globalscale ocean cruise data (G2 in our notation), Sholkovitz et al. (2012) found a consistent hyperbolic dependency between the total aerosol iron and the iron solubility, as a result of the fact that the bulk aerosol is a mixture of the "lithogenic" mineral dust (with origin from natural sources), characterized by high total iron concentration $T$ and low iron solubility $s \%$ values, and the non-lithogenic "combustion" aerosols (from anthropogenic sources), which is characterized by low $T$ and high $5 \%$. Furthermore, Chen and Siefert (2004) and Baker and Jickells (2006) noted an inverse relationship between the iron solubility in aerosols and the atmospheric dust concentrations.

Baker and Jickells (2006) hypothesized that size reduction of the transported aerosol is a result of higher deposition rate of larger particles due to gravitational settling, and consequently related to decreasing concentration during transport to regions remote from desert sources. In parallel, smaller particles being exposed to chemical processing for a longer time have a larger probability to enhance its iron solubility. Thus, higher solubility for smaller concentrations is likely to be a combined effect of the particle size effects and the acid processing reactions.

Incomplete knowledge of the iron solubilization process in atmospheric dust makes its numerical modeling challenging. Model estimates of the dust deposition in remote marine regions vary by more than a factor of 10 (e.g., Schulz et al., 2012). The current models use relatively coarse horizontal resolutions and therefore describe in less detail the highly variable features of the relevant phenomena, including the emission of the iron minerals from the soils and the mesoscale character of the atmospheric thermodynamics that drives the dust-iron solubilization process. In many modeling studies, simplifications such as the use of a constant iron fraction in the dust emissions or constant iron solubility in the atmosphere are frequently applied (Meskhidze et al., 2003; Mahowald et al., 2009; Shi et al., 2011a).

The objective of this study was to develop a model for simulating the atmospheric processing of iron-containing mineral dust at a regional scale; our focus was on the dust originating from the Sahara. For the first time, high-resolution soil mineralogy was used to calculate the emitted iron fraction 
in the dust. Furthermore, a transport equation for the free iron (the goethite and hematite content) was introduced as one of the model governing equations to parameterize the soluble iron chemical reaction as a function of the mineralogy at the dust sources. We followed here the classification of iron-containing minerals to (i) structural iron embedded in the crystal lattice of aluminosilicates and (ii) iron in oxide/hydroxide called "free-iron" (Lafon et al., 2004).

At this stage, the study did not include aerosols other than the mineral dust, such as aerosols from pollution and biomass burning, which could also contain iron and/or chemically modify the iron carried by dust. The model results were validated against field data collected during several Atlantic cruises.

\section{Atmospheric dust-iron model}

\subsection{Dust and iron emissions and transport}

For this study, the DREAM regional dust model (Nickovic et al., 2001; Nickovic, 2005; Perez et al., 2006) was extended by introducing a tracer component for the atmospheric iron. Both the dust and the iron modules are driven online as passive tracers by the NCEP Eta regional atmospheric model (Janjic, 1994 and references therein). The equations for the dust and the total and free iron concentrations are of the same form but differ in their corresponding emissions from their soil sources. The governing equations for the dust concentration and for the total and free iron concentrations include turbulent mixing, vertical and horizontal advection, and wet and dry deposition. The iron chemical reaction is simulated by a first-order equation that was developed as a function of the dust mineralogy, the cloud cover, and the solar radiation. The size distribution of the dust particles is described by eight bins with effective radii of $0.15,0.25,0.45,0.78,1.3$, 2.2, 3.8, and 7.1 $\mu \mathrm{m}$ (Tegen and Lacis, 1996). The first four bins were considered as clay particles and the remaining four as silt particles.

The dynamic part of the DREAM-IRON governing equations is given by

$$
\begin{aligned}
\frac{\partial C_{k}}{\partial t}+\Delta\left[C_{k}\right] & =\left(\frac{\partial C_{k}}{\partial t}\right)_{\text {SOURCE }} \\
\frac{\partial T_{k}}{\partial t}+\Delta\left[T_{k}\right] & =\left(\frac{\partial T_{k}}{\partial t}\right)_{\text {SOURCE }} \\
\frac{\partial F_{k}}{\partial t}+\Delta\left[F_{k}\right] & =\left(\frac{\partial F_{k}}{\partial t}\right)_{\text {SOURCE }}
\end{aligned}
$$

where $C$ is the dust concentration, $T$ is the concentration of the total iron in the dust and $F$ is the concentration of the free iron fraction in the dust. The subscript $k=1,8$ denotes the particle bins. The operator given below includes the horizontal and vertical advection and the horizontal and vertical diffusion:
$\Delta\left[\pi_{k}\right]=\boldsymbol{V} \cdot \nabla_{\mathrm{h}} \pi_{k}+\left(w-w_{\mathrm{g}}\right) \frac{\partial \pi_{k}}{\partial z}+\nabla_{\mathrm{h}} \cdot\left(K_{\mathrm{H}} \nabla_{\mathrm{h}} \pi_{k}\right)+$

$\frac{\partial}{\partial z}\left(K_{\mathrm{Z}} \frac{\partial \pi_{k}}{\partial z}\right) ; \quad \pi_{k}=\left(C_{k}, T_{k}\right.$ or $\left.F_{k}\right)$

. Here, $\boldsymbol{V}=[u, v]$ is the horizontal velocity vector; $w$ is the vertical velocity; $w_{\mathrm{g}}$ is the gravitational settling velocity; $K_{\mathrm{H}}$ and $K_{\mathrm{Z}}$ are the horizontal and vertical turbulent mixing coefficients; and $\nabla_{\mathrm{h}}$ is the horizontal nabla operator. The numerical schemes of Nickovic et al. (2001) (including the aerosol emission parameterization) were applied to Eqs. (1)(3). Equation (3) is introduced for the first time in this type of study to incorporate iron mineralogy into the parameterization of the atmospheric dust-iron model.

\subsection{Iron solubility and atmospheric processing}

Iron solubility in soils is small, approximately $0.1 \%$ on average (Fung et al., 2000), but it can increase to $80 \%$ as a result of the photo and chemical processing of iron that occurs during the atmospheric dust transport (Mahowald et al., 2005). The iron solubility in dust increases due to clouds, solar radiation and polluted air (Gao et al., 2003; Luo et al., 2005; Jickells and Spokes, 2001; Desboeufs et al., 2001; Hand et al., 2004), but it could also depend on the time that dust spends in the atmosphere (Zhuang et al., 1992; Baker and Jickells, 2006). The atmospheric chemical processing of iron occurs in clouds because they provide a relatively high acidic environment. Observations confirm the relatively high solubility of the iron found in precipitation (e.g., Saydam and Senyuva, 2002). Concerning the solar radiation influence, Zhu et al. (1997) observed higher values of soluble iron during the daytime.

We applied the first-order reaction kinetics approximation to simulate the conversion of iron into its soluble form (e.g., Hand et al., 2004):

$$
\left(\frac{d S}{d t}\right)+K(S-T)=0
$$

Here, $K$ is the decay rate coefficient and $S$ is the concentration of the soluble iron. Equations (1)-(4) are each applied to the 8 dust particle bins after assuming the same rate of decay for the particles in all of the size bins. Therefore, 32 equations in total are solved at every time step of the model. For further considerations, it is convenient to introduce the following notation: $t=\frac{T}{C}, s=\frac{S}{T}$, and $f=\frac{F}{T}$.

There are different approaches to parameterize the decay rate coefficient $K$, as indicated in the Introduction. We assumed that the decay rate coefficient consists of two parts: the first part is associated with processes dependent on the cloud cover and solar radiation $\left(K_{\mathrm{CR}}\right)$ and the second part is related to the mineralogy of the dust sources $\left(K_{\mathrm{M}}\right)$ :

$$
K=K_{\mathrm{CR}}+K_{\mathrm{M}}
$$


Similar to Hand et al. (2004), we defined the decay rate due to the cloud and solar radiation effects as

$K_{\mathrm{CR}}=\frac{1}{\tau_{\mathrm{CR}}}\left(\alpha_{\mathrm{C}}+\alpha_{\mathrm{R}}\right)$.

Here, $\alpha_{\mathrm{C}}=c$ is the model ratio of cloud cover i.e., fractional cloudiness (e.g., Boer s et al., 2010); $\alpha_{\mathrm{R}}=\frac{\left(\frac{\partial \mathrm{Temp}}{\partial t}\right)}{\left(\frac{\partial \mathrm{Temp}}{\partial t}\right)_{\text {ref }}}$, where $\left(\frac{\partial T e m p}{\partial t}\right)$ is the model temperature tendency caused by solar radiation and $\left(\frac{\partial \mathrm{Temp}}{\partial t}\right)_{\mathrm{ref}}=1{ }^{\circ} \mathrm{C} \mathrm{day}^{-1}$. Note that $\alpha_{\mathrm{C}}$ and $\alpha_{\mathrm{R}}$ are spatiotemporally dependent parameters and $\tau_{\mathrm{CR}}$ is the characteristic decay time due to the cloud and radiation effects; the decay time will be specified later.

Following Shi et al. (2011a) we developed a parameterization scheme for $K_{\mathrm{M}}$ that is a function of the iron mineralogy represented by the free-to-total iron ratio. They defined the potential iron solubility as $s_{\text {pot }}=\frac{S_{\text {SOIL }}}{T_{\text {SOIL }}} 100 \%$, where the soluble fraction, $S_{\text {SOIL }}$ was obtained by exposing soil samples to the acidic laboratory conditions for 3 days. As described by Shi et al. (2011a) multiple cycling (3 times) between acidic

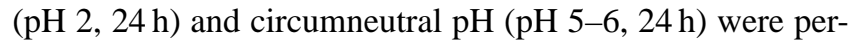
formed using $\mathrm{H}_{2} \mathrm{SO}_{4}$. These $\mathrm{pH}$ cycles were made to simulate the cycling of dust between aerosols and clouds during the dust transport.

The soil samples were collected from several African regions known to be dust sources. The sampling locations are marked in Fig. 1 with blue squares. One group of samples was collected from the Sahel region (Mali and three sites in Niger) characterized by high temperatures and relatively high precipitation. These soils were influenced by natural, intense weathering. The second soil group (from Tibesti and Western Sahara) originated from locations where soils are exposed to modest weather conditions. The third soil group (from Bodélé, Tunisia, and two sites in Libya) came from dried paleolake beds exposed to weak chemical weathering.

Shi et al. (2011a) showed that there is a relationship between the degree of chemical weathering (reflected in the free-to-total iron ratio) and $s_{\text {pot }}$ for eleven selected sampling sites in Africa:

$s_{\text {pot }}=-22.1 \times f+15.8\left(R^{2}=0.44\right)$.

The free-to-total iron ratio is an indicator of the soil maturity and the degree of chemical weathering. There was considerable spatial variability among the samples in the free-to-total iron ratio, with generally higher ratios in less weathered soils. The free-to-total iron ratios in the samples ranged from 0.13 (Libya) to 0.6 (Niger). The Sahel soils (Niger sites and Mali), which were mostly weathered, had the lowest $s_{\text {pot }}$ values. The weak weathering of the lake sediments (e.g., Bodélé, Tunisia and Libya) resulted in higher $s_{\text {pot }}$ values.

To introduce mineralogy as a factor in the iron atmospheric modeling based on the empirical relation in Eq. (7), we developed a technique to map $f$ into the model grid. For that purpose, several geospatial data were employed.
Table 1. Soil texture classes and their mass percentages of clay and silt.

\begin{tabular}{lll}
\hline Texture classes & Clay $(\%)$ & Silt $(\%)$ \\
\hline Sand & 3 & 5 \\
Loamy sand & 0 & 19 \\
Sandy loam & 10 & 26 \\
Silt loam & 12 & 66 \\
Silt & 5 & 88 \\
Loam & 18 & 41 \\
Sandy clay loam & 26 & 14 \\
Silty clay loam & 33 & 56 \\
Clay loam & 33 & 35 \\
Sandy clay & 41 & 6 \\
Silty clay & 46 & 47 \\
Clay & 61 & 19 \\
\hline
\end{tabular}

First, we calculated the iron percentages in iron-carrying minerals (illite, kaolinite, smectite, iron oxides and feldspars) from the GMINER30 global $1 \mathrm{~km}$ database (Nickovic et al., 2012). These percentages were specified for dust sources assumed to exist for the following $1 \mathrm{~km}$ USGS land cover types: low sparse grassland, bare desert, semi desert, sand desert, semi desert shrubs, and semi desert sage (Nickovic et al., 2001). The dust sources for latitudes higher than $55^{\circ}$ were defined as nonproductive dust soils. The emitted effective mineral fractions were calculated as the weighted means with respect to the clay and silt soil contents. The clay and silt values were obtained from the gridded soil texture classes in the STATSGO-FAO database in which the FAO 5 min global soil texture is remapped onto a global $30 \mathrm{~s}(\sim 1 \mathrm{~km})$ grid (USDA, 1994). Table 1 shows a correspondence between the soil texture classes and the mass percentages of clay and silt as used in the model. The values in the table were estimated from the textural triangle by combining data from Tegen et al. (2002) and Shirazi et al. (2001). The sand was ignored because it does not contribute to the longer-range dust-iron transport addressed by our study. Therefore, we assumed the emitted dust in the model to be a mixture of clay and silt particles only.

Over the North African dust sources, the total iron content in the different types of iron-containing minerals varies substantially. Table 2 shows the percentages of the total iron in the different minerals that were used in the model, and the ranges reported in the literature (Thomson and Hower, 1975; Journet et al., 2008; Paris et al., 2011). Although there are differences in the chemical reactivity of the goethite and the hematite, these minerals were here considered to be iron oxides (e.g., Claquin et al., 1999; Shi et al., 2011a).

\subsection{Total iron distribution in soil and decay rates}

By combining the Table 2 data and the mineral fractions from GMINER30, a $1 \mathrm{~km}$ grid dataset for the total iron 
Table 2. Content of total iron in different minerals as used in the model and its range based on values reported in Thomson and Hower, 1975; Journet et al., 2008; Paris et al., 2011.

\begin{tabular}{llllll}
\hline Mineral & Illite & Kaolinite & Smectite & $\begin{array}{l}\text { Goethite and Hematite } \\
\text { (clay and silt) }\end{array}$ & Feldspar \\
\hline Total Fe (\%) used in DREAM & 4.8 & 0.7 & 16.4 & 66 & 2.5 \\
Total Fe (\%) from literature & $3.38-4.65$ & $\sim 0.7$ & $2.55-23$ & $57.5-77.4$ & $0.13-0.54$ \\
\hline
\end{tabular}

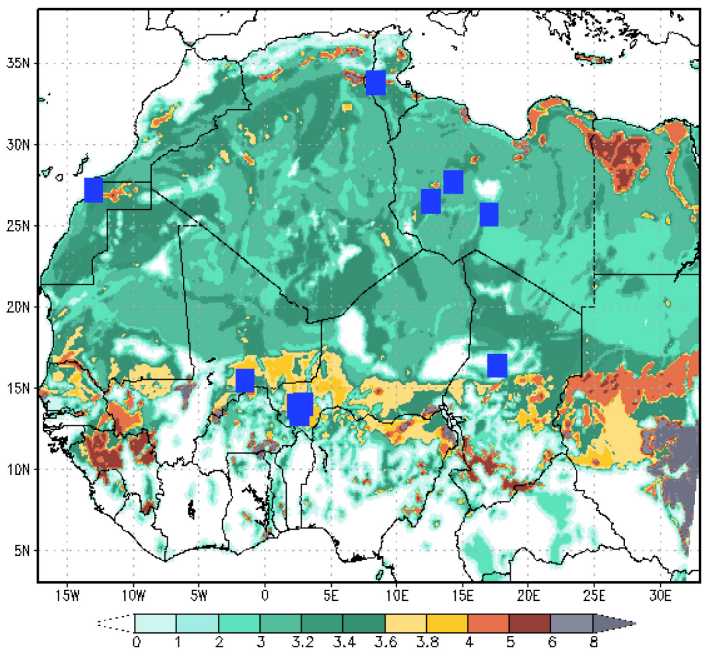

(a)

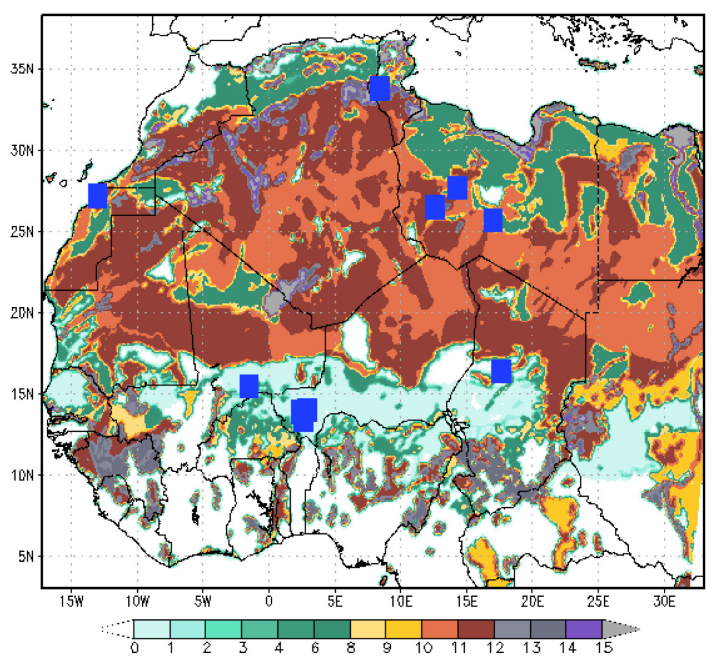

(c)

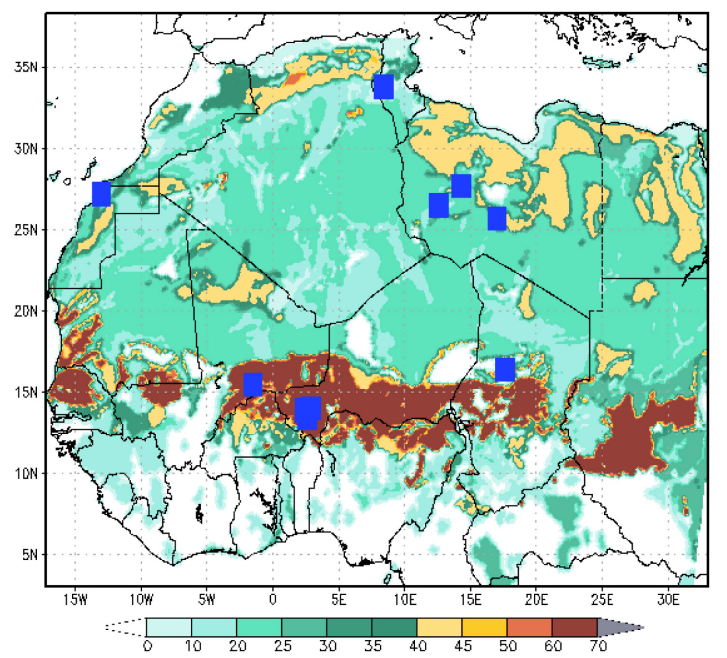

(b)

Fig. 1. Geographic distribution of iron-related soil parameters over northern Africa. (a) Total iron; (b) Free-to-total iron ratio $f$; (c) Potential solubility $s_{\text {pot }}$.

fraction, $t_{\mathrm{SO}} \times 100 \%$, in the clay-silt mixture was generated. As shown in Fig. 1a, the total iron demonstrated significant geographical variability. In most of the Sahara, the total iron ranged from 2-3.6\%, except for some parts of northern Egypt, Libya and Algeria, where the values reached $6 \%$ or more. The total iron amounts were generally higher in the Sahelian region. The GMINER30 values were within the range of the published observational evidence. Guieu et al. (2002) showed that the average observed total iron originating from Tunisia, Morocco, Niger and Algeria is $4.45 \%$. Lafon et al. (2004) reported that the total iron ranges from 6.2 to $8.7 \%$ in Saharan and Sahelian samples. Other observations indicate that the total iron in samples collected in the 


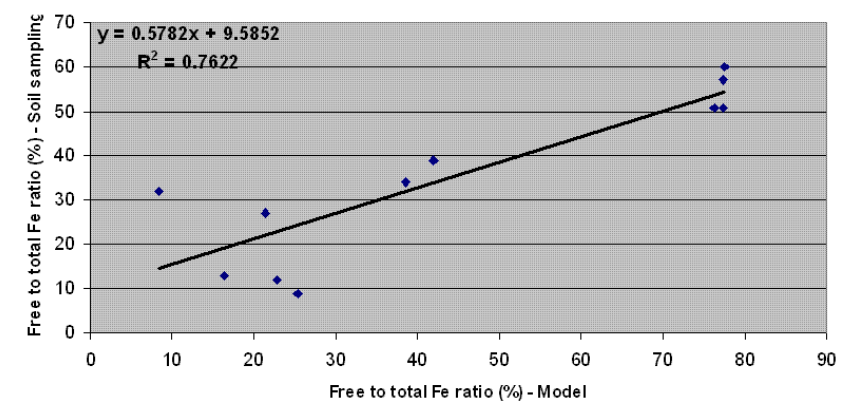

Fig. 2. Scatter diagram of observed $f$ at 11 sites and values interpolated from GMINER30 in these locations.

Sahara and the Sahel is in the range of $0.8-12.2 \%$ (Shi et al., 2011a).

Figure $1 \mathrm{~b}$ displays $f$ values mapped from GMINER30; the locations of the observation sites are marked with the blue squares. The mapping indicated that there is a belt in the Sahel with rather high $f$ values up to $\sim 0.6$; that North Africa, parts of Algeria, Libya and Egypt are characterized by $f$ values ranging from 0.4 to 0.45 ; and that the $f$ values in the remaining Saharan region varied from less than 0.1 to 0.25 . Figure 2 is the scatter diagram of the $f$ values observed at 11 sites and of the values interpolated from GMINER30 in the same locations, with strong correlation achieved between the observed and the interpolated values $\left(R^{2}=0.76\right)$. This correlation provides indirect confirmation that the GMINER30 data compare well with observations. The gridded $s_{\text {pot }}$ calculated from Eq. (7) is shown in Fig. 1c. These calculations indicated that, in general, the soils of the central Saharan belt are sources of potentially more reactive iron characterized by low free-to-total iron ratios.

The gridded values of $f$ and $s_{\text {pot }}$ were used to parameterize the iron atmospheric processing as a function of the mineralogy at the soil sources. To specify the decay rate $K_{\mathrm{M}}$, we integrated with respect to time from $t=0$ to $t_{\mathrm{pot}}$ the part of Eq. (4) addressed to the mineralogy:

$\ln \left(100 s_{\mathrm{pot}}\right)=\ln \left(100 s_{0}\right)-K_{\mathrm{M}} t_{\mathrm{pot}}$

where we assumed $s_{0}=0.1 \%$ to be a typical solubility in the soil sources (e.g., Moxim et al., 2011). $t_{\text {pot }}=75$ days has been chosen as a typical time needed for the solubility to achieve $s_{\text {pot }}$ in the atmosphere. It is within the range of values reported by other studies cited in the Introduction and it is tuned to reduce differences between observations and model simulations.

After neglecting $s_{0}$ as a small value compared to $100 \%$, we evaluated the decay rate due to the mineralogy as

$K_{\mathrm{M}}=-\frac{1}{t_{\mathrm{pot}}} \ln \left(1-\frac{s_{\mathrm{pot}}}{100}\right)$
Table 3. Group G1 of cruises from which data have been used in this study ${ }^{\mathrm{a}}$.

\begin{tabular}{lll}
\hline Cruise name & Start and end date & Start to end latitude; longitude \\
\hline JCR $^{\text {b,c }}$ & 17 to 19 Sep 2001 & $(22.7 ;-18.3)$ to $(30.8 ;-20)$ \\
PEL $^{\mathrm{d}}$ & 5 to 7 Oct 2002 & $(33.5 ;-22.7)$ to $(30.8 ;-20$ \\
M55 $(1)^{\text {e }}$ & 15 to 26 Oct 2002 & $(10.8 ;-56.2)$ to $(8.5 ; 6.6)$ \\
M55 $(2)^{\mathrm{e}}$ & 2 to 9 Nov 2002 & $(9.5 ;-24.7)$ to $(8.2 ;-18)$ \\
BUCK $^{\mathrm{f}}$ & 21 to 26 Jul 2003 & $(23 ;-27.3)$ to $(15 ;-29)$ \\
ANT23-1 & 1 to 2 Nov 2005 & $(12.3 ;-20.5)$ to $(8.7 ;-18.8)$ \\
\hline
\end{tabular}

a Only days dominated by dust (according to A. R. Baker, personal communication, 2012 and Buck et al. (2010)) are included. ${ }^{b}, \mathrm{c}$ Baker et al. (2003); ${ }^{\mathrm{e} B a k e r}$ and Jickells (2006) ; ${ }^{\mathrm{f}}$ Buck et al. (2010) ; ${ }^{\mathrm{g}}$ Baker et al. (2010).

Using Eqs. (5), (6), and (7) in (8) and assuming that $\tau=$ $t_{\text {pot }}=\tau_{\mathrm{CR}}$, we calculated the decay rate as

$K=\frac{1}{\tau}\left[\alpha_{C}+\alpha_{R}-\ln \left(1-\frac{-22.1 \times f+15.8}{100}\right)\right]$.

$K$ is a four-dimensional parameter varying spatially and temporally during the model execution.

\section{Simulation experiments}

A set of model experiments was conducted to simulate the iron atmospheric cycle for various oceanographic cruises in the Atlantic. Two groups of aerosol observations were studied. One group (hereafter called G1) relates to parts of Atlantic cruises JCR, BUCK, ANT23-1, PEL, M55 (1) and M55 (2) (Baker et al., 2003; Buck et al., 2010) in which aerosol is likely to be from the Saharan dust sources. The second group of observations (G2) represents a compilation of aerosol samples collected during various Atlantic cruises on both dusty and nondusty days (Sholkovitz et al., 2012; data shown in their Figs. 5 and 6). These observations were used to investigate how our simulations compare with the observed hyperbolic dependency between the iron solubility and the total iron loading. Table 3 summarizes the dates and the start and end points of G1 cruises for which we interpolated the model parameters, while in Table 4 are given regions of G2 cruises and their references.

For JCR, BUCK and ANT23-1 with paths closer to the African coastline, we used a smaller model domain with borders $36^{\circ} \mathrm{W}, 22^{\circ} \mathrm{E}, 3^{\circ} \mathrm{S}$ and $37^{\circ} \mathrm{N}$. For PEL, M55 (1) and M55 (2), the model domain was extended to $59.5^{\circ} \mathrm{W}$, $29.5^{\circ} \mathrm{E}, 1.5^{\circ} \mathrm{S}$ and $33.5^{\circ} \mathrm{N}$, in order to cover the longitudinal path of M55 (1). For both setups, a horizontal model resolution of 0.25 deg was applied.

For each cruise experiment, the meteorological initial and boundary conditions for the atmospheric model driver were updated daily from the gridded 0.5-deg ECMWF objective analyses archive. The simulated $24 \mathrm{~h}$ dust and iron concentrations from a previous day were used as the initial conditions for a current day. The experiments were initiated with 
Table 4. Group G2 of cruises from which data have been used in this study.

\begin{tabular}{lll}
\hline $\begin{array}{l}\text { Cruise reference number as in } \\
\text { Sholkovitz et al. (2012) }\end{array}$ & Reference & Region \\
\hline 10 & Wu et al. (2007) & $\begin{array}{l}\text { western North Atlantic } \\
\text { (Sargasso Sea) } \\
\text { Atlantic }\end{array}$ \\
12 & Chen (2004) & eastern North Atlantic \\
15 & Buck et al. (2010) & North Atlantic \\
17 & Baker et al. (2006) & North Atlantic \\
18 & Chen and Siefert (2004) & Tropical North Atlantic \\
19 & Johansen et al. (2000) & North Atlantic (Sargasso Sea) \\
21 & Sedwick et al. (2007) & Atlantic (Bermuda tower samples) \\
23 & Church, Sedwick and Sholkovitz, & \\
\hline
\end{tabular}

a zero-concentration "cold start" four days before a starting cruise date to remove model spin-up effects.

\section{Model evaluation}

There are significant sources of errors in both modeling and observations. In the dust model intercomparison studies of Uno et al. (2006) and Todd et al. (2008) the predicted surface level concentrations sometimes show differences of at least an order of magnitude. On the observational side, aerosol concentrations in general and in particular iron fraction and/or its soluble part are difficult to measure accurately at low concentrations observed (Mahowald et al., 2009; Baker and Croot, 2008). Additional uncertainty in observations is originating from the fact that the total iron was often assessed assuming its fraction in dust mass concentration to be $3.5 \%$ (e.g., Baker and Croot, 2008; Mahowald et al., 2009; Sholkovitz et al., 2012).

Therefore, when accuracy of dust-iron models is assessed, one has to draw conclusions with caution. Yet, there is a necessity to understand modeling performance in direct comparison against observations, because large gaps in ironrelated observations could be at least partly compensated by information from model simulations. Several studies report on direct point-to-point model-observations comparisons (Luo et al., 2005, 2008; Hand et al., 2004; Mahowald et al., 2009). Based on several model studies used to extrapolate observation data, Mahowald et al. (2009) concluded that annual averaged model iron surface concentrations and daily averaged observations differ by a factor of 50-1000\%. On the other hand, their study shows that in direct point-to-point comparison, scattering along the individual cruises is much smaller than for the annual averages (with most of the points falling within \pm one order of magnitude interval). Their results also indicate that the model overpredicts iron especially in places with very low concentrations and depositions.
Following the mentioned approach of direct comparison of simulated and observed parameters along the cruises, we show performance of the near-surface model total iron concentration $T$, the soluble iron concentration $S$ and the iron solubility ( $s \%$ ). Figure 3 shows $T, S, s \%$ simulated for M55 (1) when the dust was the aerosol likely to originate from Saharan dust sources. Namely, datasets JCR, ANT23-1, PEL, M55 (1) and M55 (2) include only samples which had visible Saharan dust on the filters and should therefore have dust as a major component of the total aerosol (A. Baker, personal communication, 2012). Similarly, BUCK data include only samples marked as Saharan for the air mass regime (Table 1 in Buck et al., 2010).

The cruise track and the markers indicating the positions of the cruise vessel at selected model valid times are plotted as a reference to the simulated fields.

In Fig. 3, we plotted maps valid for 12:00 UTC on 17, 21 and 25 October to illustrate how much the model variables fluctuate spatially and temporally. Only the variables over the ocean are shown. Note that the trade winds produced a typical east-west shape of the fields, although on 17 October, there was a more north-south weave-like variability of the fields. As a result of using relatively fine resolutions for the mineral sources and for the driving atmospheric model, the total iron concentration field $T$ (Fig. 3a-c) is characterized by many mesoscale structures. The patterns of the dust concentration $C$ (not shown) are similar in shape to those of $T$. Some similarities in shape between the total concentration $T$ and the soluble iron concentration $S$ are also evident (Fig. 3d-f); however, patterns such as the local maxima in the two fields are not comparable because $S$ additionally varies due to the chemical transformation. Such differences in $T$ and $S$ produce a highly variable structure of their derived field, the solubility $s \%$ (Fig. 3g-i). Considerable daily variability in $s \%$ is also observed, with the value sometimes changing several times between consecutive days (e.g., Baker et al., 2003, 2010; Baker and Jickells, 2006; Buck et al., 2010; Sholkovitz et al., 2012). 
(a)
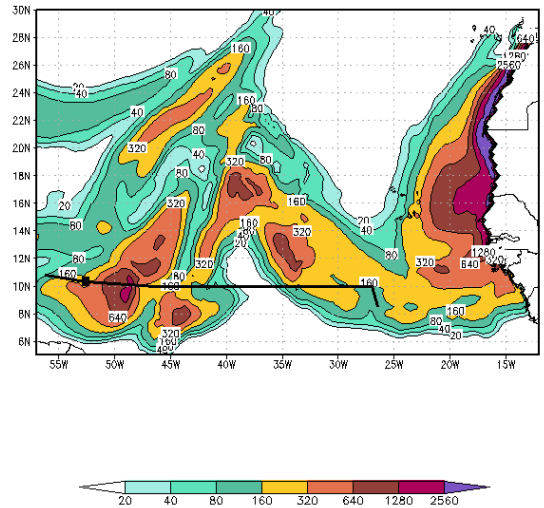

(d)
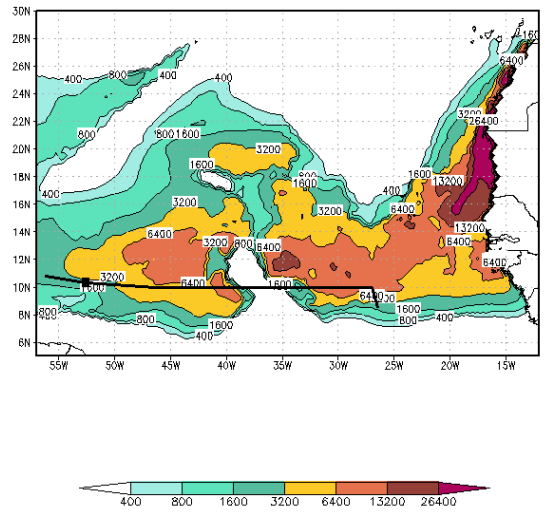

(g)
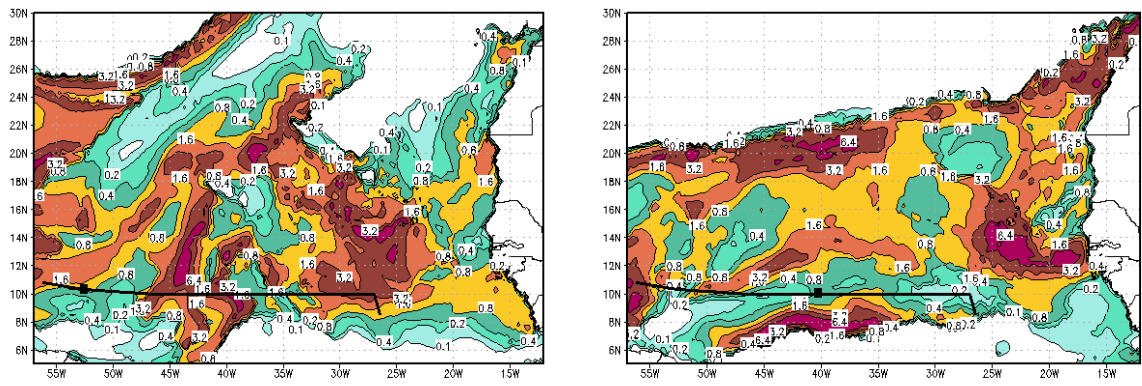

(h)
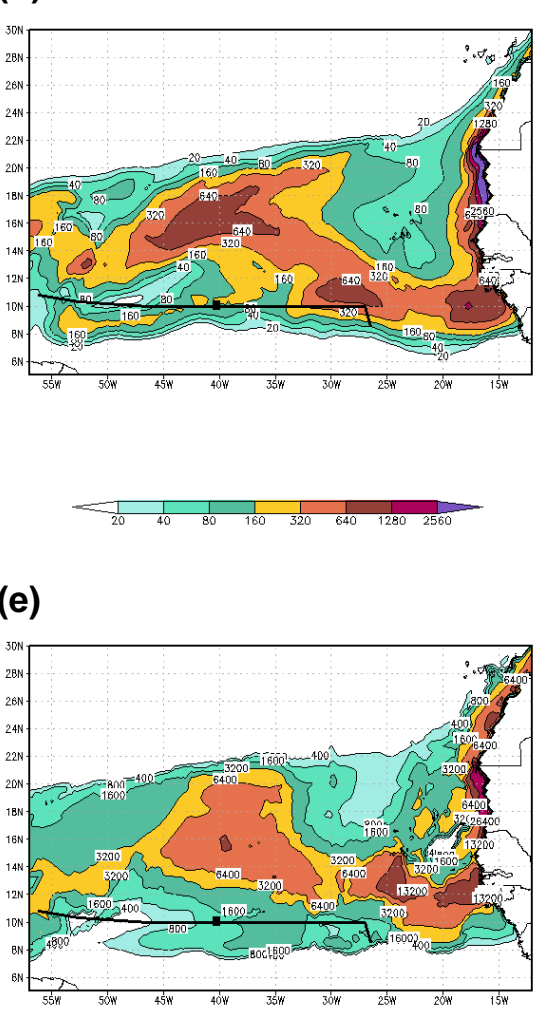

(c)

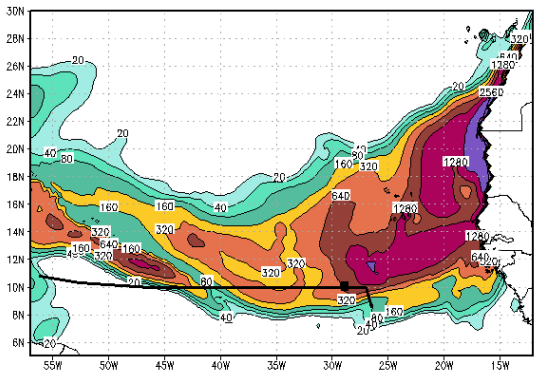

(f)

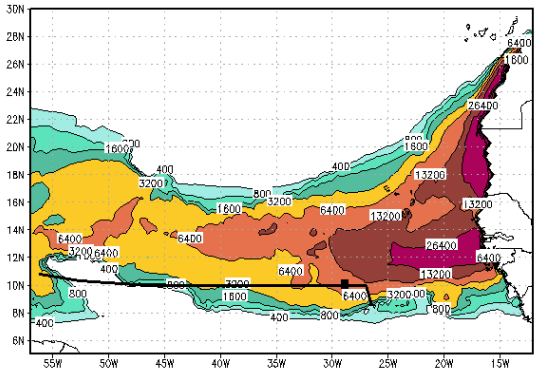

(i)
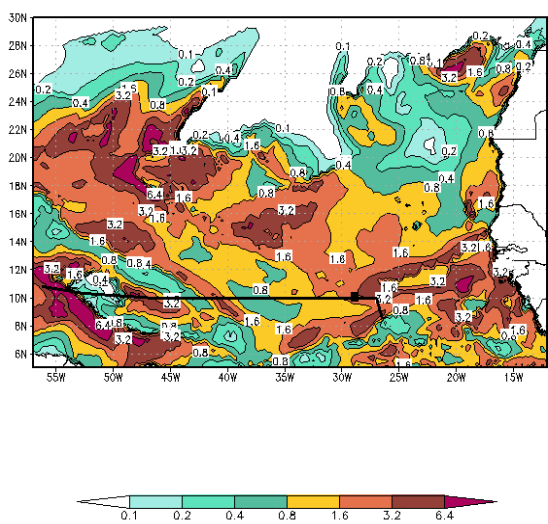

Fig. 3. Spatial and temporal features of simulated dust-related fields. (a-c): the instantaneous total iron concentration in dust $T$ (ng $\mathrm{m}^{-3}$ ) at 12:00 UTC for 17, 21 and 25 October 2002; (d-f): the same as in (a) but for the soluble iron concentration $S$ (pg $\left.\mathrm{m}^{-3}\right)$; $(\mathbf{g}-\mathbf{i})$ : the same as in (a) but for the iron solubility $s \%$.

Next, we focus on comparing the model results with the observations from the daily samples of the $C, T$ and $S$ taken during the $\mathrm{G} 1$ cruises, which provided a total of 32 identified days when dust was a dominating aerosol.
Our experiments showed that for most samples, the model dust concentration is within an order of magnitude of accuracy (Fig. 4a), with values for the bias and the root mean square error of 1 and $40 \mu \mathrm{g} \mathrm{m}^{-3}$, respectively. The scatter diagram of the same values is shown in Fig. 4b. For a single 
(a)

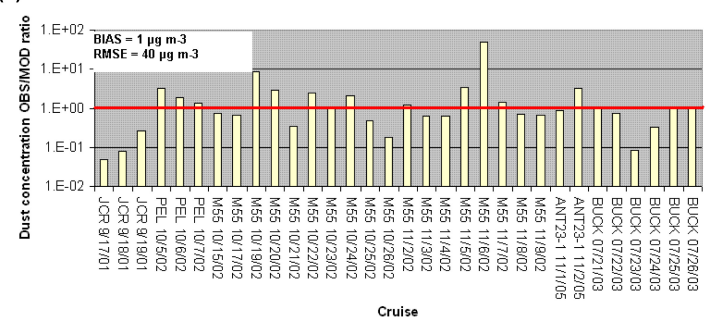

(c)

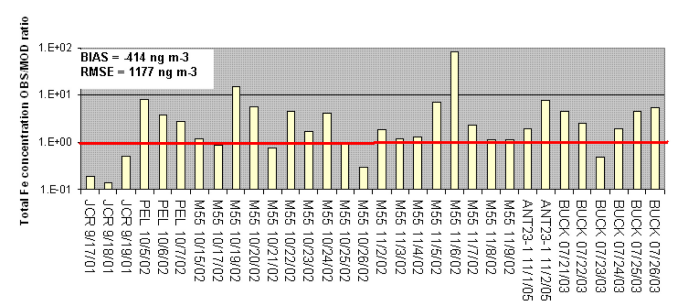

(e)

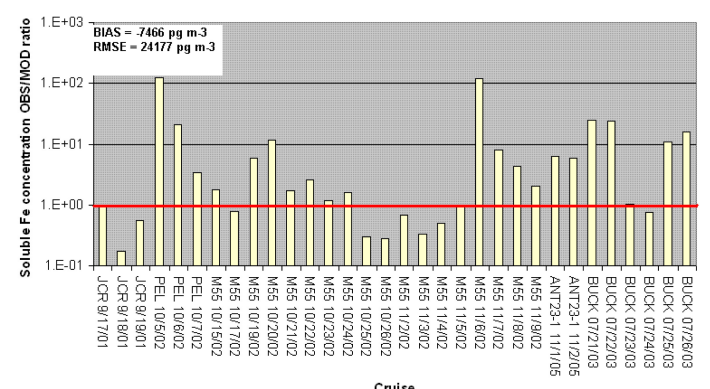

(b)

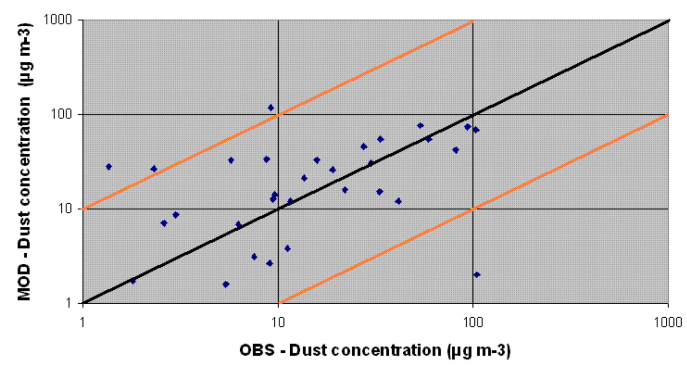

(d)

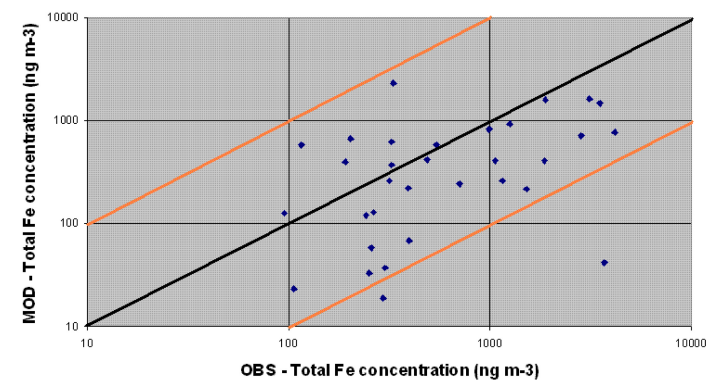

(f)

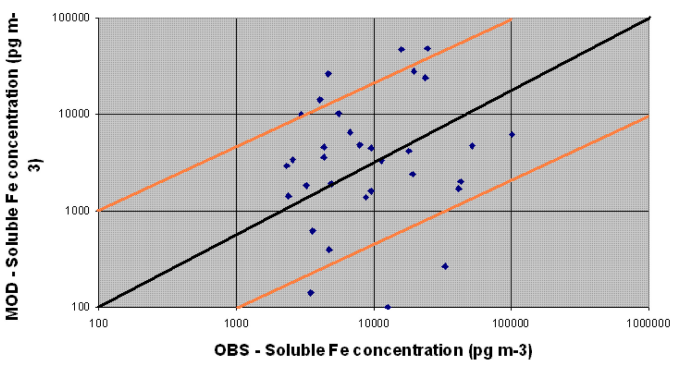

Fig. 4. Observations/model ratios of daily $C, T$ and $S$ along the $\mathrm{G} 1$ cruise paths ((a), (c) and (e) panels); model vs. observations scatter diagrams of daily $C, T$ and $S$ along the G1 cruise paths $((\mathbf{b}),(\mathbf{d})$ and (f)).

day of 6 November 2002 (M55 (2) cruise), there was an exceptionally large error (predicted $C=2 \mu \mathrm{g} \mathrm{m}^{-3}$ vs. observed $C=104 \mu \mathrm{g} \mathrm{m}^{-3}$ ), which caused large underestimates in the predictions of $T$ and $S$ for that particular day, as shown below.

The simulated total iron concentrations should in general deviate more from observations because of the uncertainties added from the specification of the iron sources. In our simulations, most of the predicted and observed daily $T$ values differed by no more than one order of magnitude (Fig. 4c), although the model generally had a tendency to under predict $T$ (bias $=-414 \mathrm{ng} \mathrm{m}^{-3}$; RMSE $=1171 \mathrm{ng} \mathrm{m}^{-3}$ ). When compared with the results of Mahowald et al. (2008) for the same range of values (10-600 $\mathrm{ng} \mathrm{m}^{-3}$ ) our experiments show less scattering, possibly because our simulations have much higher model resolution and include more detailed specification of iron sources in desert soils.
The prediction of the soluble iron concentration $S$ (Fig. 4e) is more uncertain because parameterizations of the solubility process are still based on insufficient information about the iron chemical transformations. As a result, in our experiment approximately $25 \%$ of the daily model predictions deviated from the observed daily values by one to two orders of magnitude, leading to negative bias and RMSE values being larger than those of the $C$ and the $T$ (bias $=-7466 \mathrm{pg} \mathrm{m}^{-3}$; RMSE $=24771 \mathrm{pg} \mathrm{m}^{-3}$ ).

In Fig. 5, we show the soluble and total iron values from the Atlantic cruises in Sholkovitz et al. (2012) (shown in their Fig. 5b) combined with our model data interpolated along the path of the G1 cruises (note that the G2 dataset in our analysis also include most of the G1 data). Most of the model values reproduced the observed hyperbolic trend, which justifies the suitability of the parameterization methods developed in this study. 


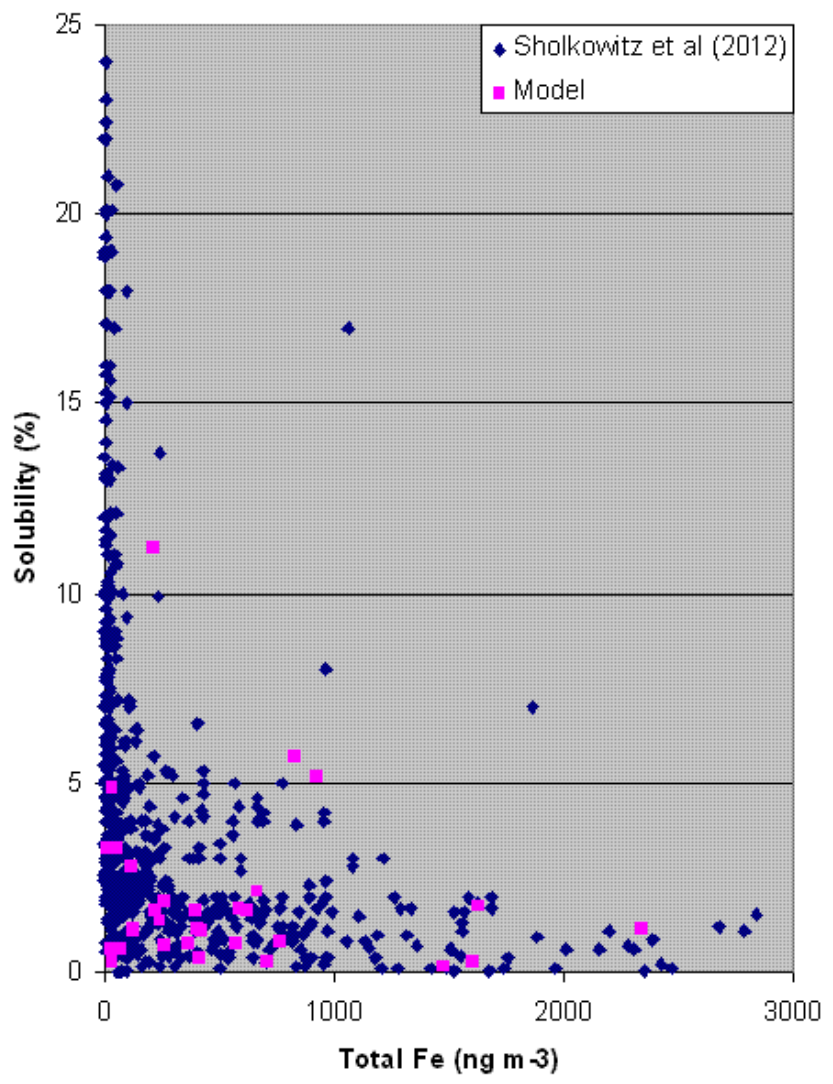

Fig. 5. Fe solubility versus total Fe for the Atlantic sites/cruises. The plotted two groups of data: blue diamonds are from datasets 15, 16, 17, 18, 21, 22, 23 and unpublished data of Powell and Baker, as shown in Sholkovitz et al. (2012; Fig. 5b); pink squares are simulated values.

In Fig. 6, we plot together their data and our simulated values. For observations where the solubility gets higher values, the samples had spent at least five days over the ocean before collection, thus aerosol was exposed to relative longer atmospheric processing (see A. Baker description at http:// www.uea.ac.uk/ e 780/solubility.htm). The model values are concentrated in the lower right quadrant (higher $C$ and lower $s \%$ ) and in general follow the observed trend for higher concentrations. Actually, the model values group mainly around observations of aerosol originating from Sahara because in our parameterization the influence of other aerosols originating from anthropogenic sources is neglected. Ito (2013) however showed that his model which includes iron-containing aerosols from shipboard pollution was able to reproduce the highly soluble part of the hyperbolic trend, demonstrating so the importance of including the anthropogenic aerosol.

Although the model is applied over Northern Africa (Sahara, Sahel) and subtropical North Atlantic, our parameterization of the iron faith in the atmosphere is not specifically addressed to any particular geographic region. Certainly, the atmospheric driving forces for the iron dissolution are spe-

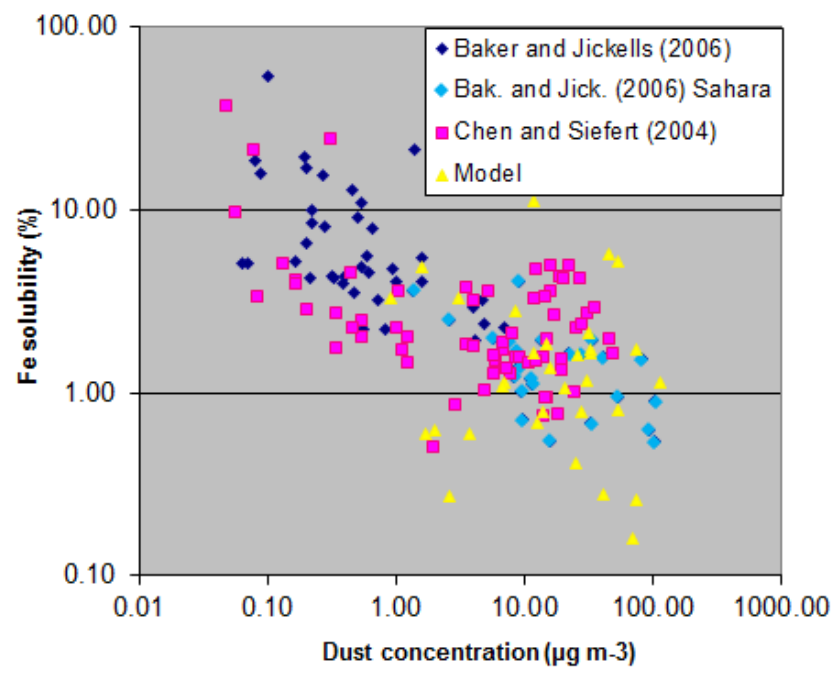

Fig. 6. Iron solubility versus dust concentration. Light and dark blue diamonds are observations from Baker and Jickells (2006) (originating from Sahara and from other sources, respectively) and pink squares are observations from Chen and Siefert (2004). Yellow triangles are the model values. Baker and Jickells (2006) observations for dust concentration smaller than about $\mu \mathrm{g} \mathrm{m}^{-3}$ relate to samples that had spent at least 5 days over the ocean before collection.

cific for a selected geographic domain such as much less clouds coverage than in the equatorial and mid-latitude areas (and consequently less influence on iron), or a specific incident angle of the solar radiation to the earth surface in the subtropics.

In order to explore how in our simulations the iron processing reacts to different effects, we evaluated a set of sensitivity experiments for the M55 cruise by executing the model without clouds, with constant $\mathrm{Fe}$ in sources and without radiation, and then compared the results with those of the reference model containing all three effects acting together (Fig. 7). The shown graph indicates that the impact of clouds is marginal due to prevailing cloud-free conditions. With the constant $3.5 \%$ iron in the sources used, the soluble values drop down by about $20 \%$ or less. Finally, with no radiation effects included, the soluble iron reduces for about $40 \%$.

\section{Summary}

In this study, we extended a mineral dust atmospheric model by adding a component for the atmospheric cycle of iron carried by dust. Unlike studies using global models with coarse resolutions, we performed experiments using a regional model with a horizontal resolution fine enough to resolve the mesoscale atmospheric dynamics and to more accurately describe the emission, transport and deposition of the dust and iron. The iron fractions in desert sources were estimated using detailed geographic distributions of the major soil minerals. This approach considerably improves the 


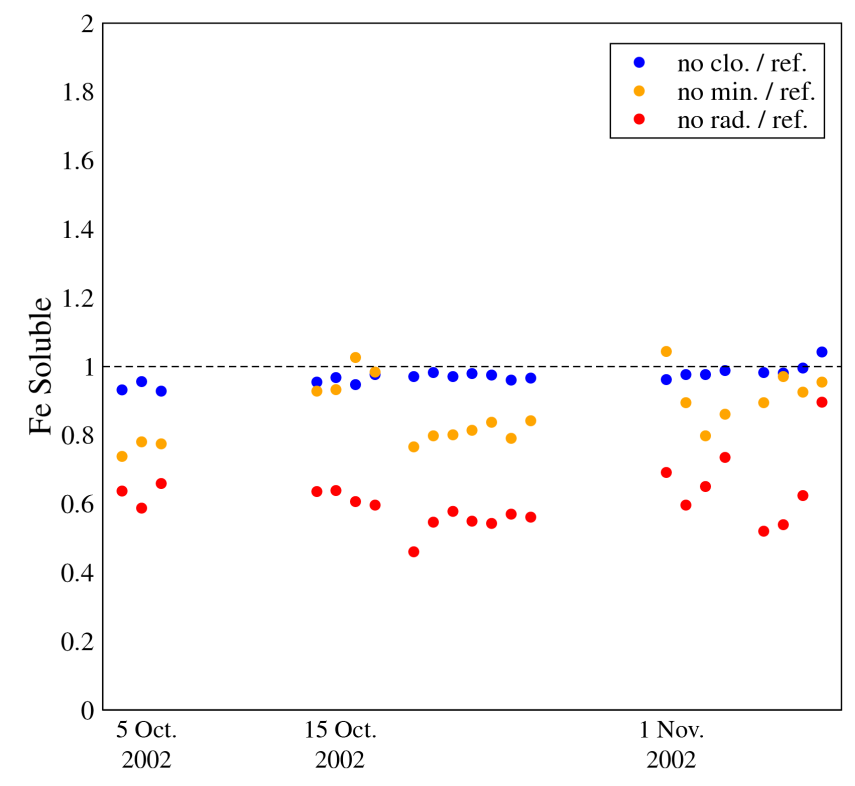

Fig. 7. Ratios of iron soluble concentrations without/with clouds (blue dots), without/with variable mineralogy (orange dots), and without/with radiation (red dots) included.

usual practice of setting a constant value for the iron content in soils. Furthermore, we developed a parameterization method that defines the decay rate coefficient for iron reduction as a function of the dust mineralogy, cloud processing and solar radiation. The rate coefficient was designed to vary in space and time during the model execution.

Results from the dust-iron modeling experiments were compared with observations collected along parts of several Atlantic Ocean cruise routes dominated by dust aerosol. The predicted dust-iron parameters, especially the iron solubility, showed high temporal and spatial variability. The model daily concentrations of the dust aerosol and of the total and soluble iron interpolated along the cruse routes generally showed good agreement with the sampled data. However, the total and the soluble iron were underestimated to some degree, possibly because of eventual smaller iron emissions at the soil origins. We also demonstrated that the simulated relationship between the solubility and the total iron amount is generally comparable to the observed hyperbolic trend for lower concentrations. This study was solely focused on desert dust because we neglected the influence of other aerosols originating from anthropogenic, biomass burning and volcanic sources that could contribute to the atmospheric iron cycle (Jickells and Spokes, 2001).

Acknowledgements. The content of this article does not necessarily reflect the opinion of the first author's organization. The authors wish to thank Alex Baker for providing parts of observational data used in this study. This study was partly funded by the project "Studying climate change and its influence on the environment: impacts, adaptation and mitigation" (43007) financed by the
Ministry of Education and Science of the Republic of Serbia within the framework of integrated and interdisciplinary research for the period 2011-2014.

Edited by: M. Kanakidou

\section{References}

Baker, A. R. and Croot, P. L.: Atmospheric and marine controls on aerosol iron solubility in seawater, Mar. Chem., 120, 4-13, doi:10.1016/j.marchem.2008.09.003, 2008.

Baker, A. R. and Jickells, T. D.: Mineral particle size as a control on aerosol iron solubility, Geophys. Res. Lett., 33, L17608, doi:10.1029/2006GL026557, 2006.

Baker, A. R., Kelly, S. D., Biswas, K. F., Witt, M., and Jickells, T. D.: Atmospheric deposition of nutrients to the Atlantic Ocean, Geophys. Res. Lett., 30, 2296, doi:10.1029/2003GL018518, 2003.

Baker, A. R., Jickells, T. D., Witt, M., and Linge. K. L.: Trends in the solubility of iron, aluminium, manganese and phosphorus in aerosol collected over the Atlantic Ocean, Marine Chem., 98, 43-58, 2006.

Baker, A. R., Lesworth, T., Adams, C., Jickells, T. D., and Ganzeveld, L.: Estimation of atmospheric nutrient inputs to the Atlantic Ocean from $50^{\circ} \mathrm{N}$ to $50^{\circ} \mathrm{S}$ based on large scale field sampling: fixed nitrogen and dry deposition of phosphorus, Global Biogeochem. Cy., 24, GB3006, doi:10.1029/2009GB003634, 2010.

Boers, R., de Haij, M. J., Wauben, W. M. F., Baltink, H. K., van Ulft, L. H., Savenije, M., and Long, C. N.: Optimized fractional cloudiness determination from five ground based remote sensing techniques, J. Geophys. Res., 115, D24116, doi:10.1029/2010JD014661, 2010.

Buck, C. S., Landing, W. M., Resing, J. A., and Measures, C. I.: The solubility and deposition of aerosol $\mathrm{Fe}$ and other trace elements in the North Atlantic Ocean: Observations from the A16N CLIVAR/CO2 repeat hydrography section, Marine Chem., 120, 57-70, 2010.

Claquin, T., Schulz, M., and Balkanski, Y. J.: Modeling the mineralogy of atmospheric dust sources, J. Geophys. Res., 104, 2224322256, 1999.

Chen, Y: Sources and fate of atmospheric nutrients over the remote oceans and their role on controlling marine diazotrophic microorganisms, PhD Thesis, University of Maryland, USA, 2004.

Chen, Y. and Siefert, R. L.: Seasonal and spatial distributions and dry deposition fluxes of atmospheric total and labile iron over the tropical and subtropical North Atlantic Ocean, J. Geophys. Res., 109, D09305, doi:10.1029/2003JD003958, 2004.

Desboeufs, K. V., Losno, R., and Colin, J. L.: Factors influencing aerosol solubility during cloud processes, Atmos. Environ., 35, 3529-3537, 2001.

Fan, S.-M., Moxim, W., and Levy, H.: Aeolian input of bioavailable iron to the ocean, Geophys. Res. Lett., 33, L07602, doi:10.1029/2005GL024852, 2006.

Fung, I., Meyn, S. K., Tegen, I., Doney, S., John, J., and Bishop, J.: Iron supply and demand in the upper ocean, Global Biogeochem. Cy., 14, 281-295, 2000.

Gao, Y., Fan, S.-M., and Sarmiento, J. L.: Aeolian iron input to the ocean through precipitation scavenging: A modeling perspective 
and its implication for natural iron fertilization in the ocean, $\mathrm{J}$. Geophys. Res., 108, 4221, doi:10.1029/2002JD002420, 2003.

Guieu, C., Loye-Pilot, C., Ridame, C., and Thomas, C.: Chemical characterization of the Saharan dust end-member: Some biogeochemical implications for the western Mediterranean Sea, J. Geophys. Res., 107, 4258, doi:10.1029/2001JD000582, 2002.

Hand, J. L., Mahowald, N. M., Chen, Y., Siefert, R. L., Luo, C., Subramaniam, A., and Fung, I.: Estimates of atmosphericprocessed soluble iron from observations and a global mineral aerosol model: Biogeochemical implications, J. Geophys. Res., 109, D17205, doi:10.1029/2004JD004574, 2004.

Ito, A.: Global modeling study of potentially bioavailable iron input from shipboard aerosol sources to the ocean, Global Biogeochem. Cy., 27, 1-10, doi:10.1029/2012GB004378, 2013.

Ito, A. and Feng, Y.: Role of dust alkalinity in acid mobilization of iron, Atmos. Chem. Phys., 10, 9237-9250, doi:10.5194/acp-109237-2010, 2010.

Janjic, Z. I.: The step-mountain Eta coordinate model: Further developments of the convection, viscous sublayer and turbulence closure schemes, Mon. Weather Rev., 122, 927-945, 1994.

Jickells, T. and Spokes, L.: Atmospheric iron inputs to the oceans, in: Biogeochemistry of Iron in Seawater, Turner, D.R. and Hunteger, K. (Eds.), John Wiley and Sons, Ltd., Chichester, UK, 85121, 2001

Johansen, A. M., Siefert, R. L., and Hoffmann, M. R.: Chemical composition of aerosols collected over the tropical North Atlantic Ocean, J. Geophys. Res., 105, 15277-15312, 2000.

Journet, E., Desboeufs, K., Caquineau, S., and Colin, J.-L.: Mineralogy as a critical factor of dust iron solubility, Geophys. Res. Lett., 35, L07805, doi:10.1029/2007GL031589, 2008.

Lafon, S., Rajot, J. L., Alfaro, S. C., and Gaudichet, A.: Quantification of iron oxides in desert aerosols, Atmos. Environ., 38, 12111218, doi:10.1016/j.atmosenv.2003.11.006, 2004.

Luo, C., Mahowald, N., Meskhidze, N., Chen, Y., Siefert, R. L., Baker, A. R., and Johansen, A.: Estimation of iron solubility from observations and a global aerosol model, J. Geophys. Res., 110, D23307, doi:10.1029/2005JD006059, 2005.

Luo, C., Mahowald, N., Bond, T., Chuang, P. Y., Artaxo, P., Siefert, R., Chen, Y., and Schauer, J.: Combustion iron distribution and deposition, Global Biogeochem. Cy., 22, GB1012, doi:10.1029/2007GB002964, 2008.

Mahowald, N. M., Baker, A. R., Bergametti, G., Brooks, N., Duce, R. A., Jickells, T. D., Kubilay, N., Prospero, J. M., and Tegen, I.: Atmospheric global dust cycle and iron inputs to the ocean, Global Biogeochem. Cy., 19, GB4025, doi:10.1029/2004GB002402, 2005.

Mahowald, N. M., Engelstaedter, S., Luo, C., Sealy, A., Artaxo, P., Benitez-Nelson, C., Bonnet, S., Chen, Y., Chuang, P. Y., Cohen, D. D., Dulac, F., Herut, B., Johansen, A. M., Kubilay, N., Losno, R., Maenhaut, W., Paytan, A., Prospero, J. M., Shank, L. M., and Siefert, R. L.: Atmospheric iron deposition: Global distribution, variability, and human perturbations, Ann. Rev. Marine. Sci., 1, 245-278, doi:10.1146/annurev.marine.010908.163727, 2009.

Meskhidze N., Chameides, W. L., Nenes, A., and Chen, G.: Iron mobilization in mineral dust: Can anthropogenic $\mathrm{SO}_{2}$ emissions affect ocean productivity?, Geophys. Res. Lett., 30, 2085, doi:10.1029/2003GL018035, 2003.

Moxim, W. J., Fan, S. M., and Levy II, H.: The meteorological nature of variable soluble iron transport and deposition within the North Atlantic Ocean basin, J. Geophys. Res., 116, D03203, doi:10.1029/2010JD014709, 2011.

Nickovic, S.: Distribution of dust mass over particle sizes: Impacts on atmospheric optics, paper presented at Fourth ADEC Workshop: Aeolian Dust Experiment on Climate Impact, Ministry of the Environ., Nagasaki, Japan, 357-360, 2005.

Nickovic, S., Kallos, G., Papadopoulos, A., and Kakaliagou, O.: A model for prediction of desert dust cycle in the atmosphere, J. Geophys. Res., 106, 18113-18130, 2001.

Nickovic, S., Vukovic, A., Vujadinovic, M., Djurdjevic, V., and Pejanovic, G.: Technical note: High-resolution mineralogical database of dust-productive soils for atmospheric dust modeling, Atmos. Chem. Phys., 12, 845-855, doi:10.5194/acp-12-8452012, 2012.

Paris, R., Desboeufs, K. V., and Journet, E.: Variability of dust iron solubility in atmospheric waters: Investigation of the role of oxalate organic complexation, Atmos. Environ. 45, 6510-6517, 2011.

Perez, C., Nickovic, S., Pejanovic, G., Baldasano, J. M., and Ozsoy, E.: Interactive dust-radiation modeling: A step to improve weather forecasts, J. Geophys. Res., 111, D16206, doi:10.1029/2005JD006717, 2006.

Saydam, A. C. and Senyuva, H. Z.: Deserts: Can they be the potential suppliers of bioavailable iron?, Geophys. Res. Lett., 29, 1524, doi:10.1029/2001GL013562, 2002.

Schulz, M., Prospero, J. M., Baker, A. R., Dentener, F., Ickes, L., Liss, P. S., Mahowald, N. M., Nickovic, S., Pìrez García-Pand, C., Rodríguez, S., Sarin, M., Tegen, I., and Duce, R. A.: Atmospheric transport and deposition of mineral dust to the ocean: Implications for research needs, Environ. Sci. Technol., 46, 1039010404, doi:10.1021/es300073u, 2012.

Sedwick, P. N., Sholovitz, E. R., and Church, T. M.: Impact of anthropogenic combustion emissions on the fractional solubility of aerosol iron: evidence from the Sargasso Sea, Geochem. Geophys. Geosyst., 8, Q10Q06, doi:10.1029/2007GC001586, 2007.

Shi, Z., Krom, M. D., Bonneville, S, Baker, A. R., Bristow, C., Drake, N., Mann, G., Carslaw, K., McQuaid, J. B., Jickells, T., and Benning, L. G.: Influence of chemical weathering and aging of iron oxides on the potential iron solubility of Saharan dust during simulated atmospheric processing, Global Biogeochem. Cy., 25, GB2010, doi:10.1029/2010GB003837, 2011a.

Shi, Z. B., Bonneville, S., Krom, M. D., Carslaw, K. S., Jickells, T. D., Baker, A. R., and Benning, L. G.: Iron dissolution kinetics of mineral dust at low $\mathrm{pH}$ during simulated atmospheric processing, Atmos. Chem. Phys., 11, 995-1007, doi:10.5194/acp11-995-2011, 2011b.

Shi, Z., Krom, M. D., Jickells, T. D., Bonneville, S., Carslaw, K. S., Mihalopoulos, N., Baker, A. R., and Benning, L. G.: Impacts on iron solubility in the mineral dust by processes in the source region and the atmosphere: A review, Aeol. Res., 5, $21-$ 42, doi:10.1016/j.aeolia.2012.03.001, 2012.

Shirazi, M. A., Boersma, L., and Johnson, C. B.: Particle size distributions: Comparing texture systems, adding rock, and predicting soil properties, Soil Sci. Soc. Am. J., 65, 300-310, 2001.

Sholkovitz, E. R., Sedwick, P. N., Church, T. M., Baker, A. R., and Powell, C. F.: Fractional solubility of aerosol iron: Synthesis of a global-scale data set, Geochim. Cosmochim. Acta, 89, 173-189, doi:10.1016/j.gca.2012.04.022, 2012. 
Spokes, L.J., Jickells, T. D., and Lim, B.: Solubilization of aerosol trace metals by cloud processing: A laboratory study, Geochim. Cosmochim. Acta, 58, 3281-3287, 1994.

Tegen, I. and Lacis, A. A.: Modeling of particle size distribution and its influence on the radiative properties of mineral dust aerosol, J. Geophys. Res., 101, 19237-19244, 1996.

Tegen, I., Harrison, S. P., Kohfeld, K., Prentice, I. C., Coe, M., and Heimann, M.: Impact of vegetation and preferential source areas on global dust aerosol: Results from a model study, J. Geophys. Res., 107, 4576, doi:10.1029/2001JD000963, 2002.

Thomson, G. R. and Hower, J.: The mineralogy of glauconite, Clays Clay Miner., 23, 289-300, 1975.

Todd, M. C., Bou Karam, D., Cavazos, C., Bouet, C., Heinold, B., Baldasano, J. M., Cautenet, G., Koren, I., Perez, C., Solmon, F., Tegen, I., Tulet, P., Washington, R., and Zakey, A.: Quantifying uncertainty in estimates of mineral dust flux: An intercomparison of model performance over the Bodélé Depression, northern Chad, J. Geophys. Res., 113, D24107, doi:10.1029/2008JD010476, 2008.
Uno, I., Wang, Z., Chiba, M., Chun, Y. S., Gong, S. L., Hara, Y., Jung, E., Lee, S.-S., Liu, M., Mikami, M., Music, S. Nickovic, S. Satake, S., Shao, Y., Song, Z., Sugimoto, N., Tanaka, T., and Westphal, D. L.: Dust model intercomparison (DMIP) study over Asia: Overview, J. Geophys. Res., 111, D12213, doi:10.1029/2005JD006575, 2006.

US Department of Agriculture (USDA): State soil geographic (STATSGO) data base-data use information, miscellaneous publication number 1492 (rev. ed.): Fort Worth, Texas, Natural Resources Conservation Service (variously paged), 1994.

Wu, J., Rember R., and Cahill, C.: Dissolution of aerosol iron in surface waters of the North Pacific oceans as determined by a semicontinuous flow-though method, Global Biochem. Cy., 21, GB4010, doi:10.1029/2006GB002851, 2007.

Zhuang, G., Yi, Z., Duce, R. A., and Brown, P. R.: Link between iron and sulphur cycles suggested by detection of $\mathrm{Fe}(\mathrm{II})$ in remote marine aerosols, Nature, 355, 537-539, 1992.

Zhu, X, Prospero, J., Millero, F., and Millero, F. J.: Daily variability of soluble $\mathrm{Fe}$ (II) and soluble total Fe in North Africa dust in the trade winds at Barbados, J. Geophys. Res., 102, 297-305, 1997. 